\title{
Adaptive Online Module Prototype for Learning Unified Modelling Language (UML)
}

\author{
Arief Hidayat $^{1}$, Victor Gayuh Utomo ${ }^{2}$ \\ ${ }^{1}$ Department of Information System, STIMIK Pro Visi Semarang, Indonesia \\ ${ }^{2}$ Department of Computer Engineering, STIMIK Pro Visi Semarang, Indonesia
}

\begin{tabular}{l}
\hline \hline Article Info \\
\hline Article history: \\
Received Apr 19, 2016 \\
Revised Aug 23, 2016 \\
Accepted Oct 7, 2016
\end{tabular}

\section{Keyword:}

Adaptive

Learning

Online module

Prototype

Unified modelling language

\begin{abstract}
Every student has their own learning style. Some students may prefer to read the learning material while some other students may prefer to discuss with their colleagues to help them understanding the information more effectively. One of the learning materials is Unified Modeling Language or UML. UML is an industry standard language to specify, visualize, construct, and document the artifacts of software systems. Today, many UML online learning sites are designed to give added information to students other than face-to-face interaction in the classroom. However, most of UML materials provided by the online learning resources are limited to text-based material which is suitable only for students with verbal learning styles. This research aims to identify and analyze the needs before developing a prototype of an adaptive online module. The research is also driven by the need to develop a prototype of adaptive online module that is based on the student's learning style categories in order to help students understand UML better. The result of this research is a prototype of adaptive online module which will identify students' learning styles and lead the students to learning environment that suits their learning style.
\end{abstract}

Copyright (c) 2016 Institute of Advanced Engineering and Science. All rights reserved.

Corresponding Author:

Arief Hidayat,

Department of Information System, STIMIK Pro Visi,

Pattimura Street 32-34, Semarang-50127, Indonesia.

Email: rifmillenia@gmail.com

\section{INTRODUCTION}

Unified Modeling Language (UML) has been widely accepted in process modeling software requirements, and now the industry standard for modeling all aspects of information systems [1]. UML is an industry standard language to specify, visualize, construct, and document the artifacts of software systems. UML is classified as Model-Driven development, modeling that emphasizes software design before coding [2].

Currently, software engineering course at undergraduate level, has subject about object-oriented programming and modelling software. The subject introduces students to modelling tools, such as Data Flow Diagrams (DFD), Business Activity Model, Work Practice Model, Logical Data Model (LDM), as the basic concepts for modeling. Typically, students enrolled under Computer Science or Information Systems study program learn basic programming concepts (e.g. C or C \# language), after which they will learn the concept of object-oriented technology. At this stage, naturally, study program will add the subject of the Unified Modeling Language (UML) in the software engineering course.

Today, students are encouraged to develop their knowledge by finding additional learning materials while completing tasks and exercises at the time of study. This applies to a numerous of subjects including software engineering education. This research is motivated by the problems that arise in learning object-oriented programming and modeling using UML. The available online learning resources for object- 
oriented programming and UML are limited in the form of HTML-based text. Text-based online learning resources are fail to recognize the differences in the learning styles of each student. It may be easier for student A to learn a material through reading while student B may be pleased and get better understanding discussing with other students on a particular matter. Though study program generally allocate a half from 14-week meetings for students to learn the UML, it is considered insufficient for students to understand the knowledge of the UML well. Realizing personalization and student learning styles is important, this research design a prototype of adaptive online module to help students learn better UML.

Research associated with web-based adaptive learning is more interesting as the increasing usage of e-learning for supporting distance learning process which inspire Indonesian government to publish Permendikbud Indonesia No. 24 of 2012 on the Implementation of Distance Learning by College. By the advance development in cloud computing and e-learning technology, using the university and college resources, smart learning system and enhance learning system with pro-active services can be built to the benefit of the students and faculty. The concept may range from a smart classroom, which allow teaching process equipped with computer and audiovisual devices (PC with internet access), to a smart campus, which allow students to create a social relations among friends and people for sharing their interests and activities [3].

The aim of conducting this research is to identify and analyze the needs to develop a prototype adaptive online module. The research also aims to design a prototype of adaptive online module based on the student's learning style categories in order to help students understand UML better.

\section{RELATED WORK}

In 2004 Wang, Li and Chang develop CooTutor that focuses on combining adaptive presentation and $3 \mathrm{D}$ visualization in a web-based learning environments to improve the learning outcomes of students. CooTutor are specifically designed to help spatial reasoning learners on the topic of geometry in computer graphics. This system takes advantage of web-based learning environment which means learning can happen at any place and any time. CooTutor requires a platform/environment that provides learners with 3D visualization-especially for geometry topics. CooTutor designed so that the concept be sorted according to the state of knowledge of learners. Sorted objects at this level is not directly study the material, but the concept [4]. Therefore, this stage is also called sequencing concepts. After determining the concept of what should be delivered, the selection of material processed. The next appropriate learning materials chosen to illustrate the concept. This is similar to the two-level curriculum sequencing (ie knowledge sequencing and task sequencing) mentioned by Brusilovsky [5].

Canavan [6] developed a model of interaction in Personalized Adaptive e-Learning Service (Apels). Interaction models using Honey Mumford learning styles as a basis for the design Apels. Apels used by the Knowledge and Data Engineering Group in the Department of Computer Science at Trinity College Dublin. This system is used by students who learn database programming using SQL. Apels users are asked to participate in surveys of Honey Mumford learning styles which summarizes learner style appropriately to follow the four categories of learning styles - Activist, Reflector, Theorist or Pragmatist. For example, if the value of 50 students in the category Activist, 40 in the category Reflector, 75 in the category Theorist and 30 to category Pragmatist. As example, if a student is considered in the category Theorist than the student can proceed to learning materials designed for students with Theorist category. However, students are given freedom in such a way to define the concept of learning to be taken. Therefore, the system is no longer fully adaptive, when a student may choose to explore other material by preference (not defined by the category of learning styles).

In 2012, Bontchev and Vassileva [7] developed adaptive edutainment in UML, designed and delivered using ADOPTA (Adaptive Technology-Echanced Platform for Edutainment). Adaptive edutainment improves traditional method of e-learning substantially. Adaptive e-learning provides different educational content for each learner or groups of learners based on specific learning character features, such as learning styles. On the other hand, adaptive edutainment making e-learning more interesting and effective, as far as students acquire skills and practical knowledge without the traditional businesses to learn the theory and exercises. ADOPTA (Adaptive Technology-enhanced Platform for edutainment), which is developed at the University of Sofia, Bulgaria, uses learning style and student's performance to adjust the learning delivery. ADOPTA shows storyboard navigation and content selection in an adaptive manner. This study also uses Honey and Mumford learning styles [8] (consists of activist, theoretical, pragmatic and reflectors). According to Honey and Mumford, student may have a dominant preferred style but may add other elements too. Thus, the use of ADOPTA and game framework creates a new, direct, fast and easy edutainment adaptive learning. 


\section{LEARNING STYLES}

In an e-learning environment, provide materials for each learner based on their individual preferences is proven to be beneficial. Thus, many have made research upon the important problem, automatic detection of learning styles of an individual [9].

The online module prototype has adaptive capabilities which means it will adapt to the user, especially in terms of the learning style of the user. Learning style model puts students in a category where the student is mostly suited with some scales related to how the students receive and process information [10].

Student fill the Felder and Solomon Learning Styles questionnaire to determine its learning style. Questionnaires result will classify student into four main categories-active $\rightarrow$ reflective, sensing $\rightarrow$ intuitive, visual $\rightarrow$ verbal and global $\rightarrow$ sequential learner. Based on the result, the prototype module will give the student the appropriate adaptive online learning activities according to student's category. This research chooses Felder-Solomon Index of Learning Style (ILS) questionnaire because of the range of given values to provide flexibility to the human personality (in this case learning style). Humans tend to have a tendency but not for permanent personality [11].

The prototype of Adaptive Online Module use Felder Solomon questionnaire due to these reasons:

1. Felder-Solomon Learning Style Model is often used to provide learning styles adaptability in e-learning environment [11].

2. Various higher institutions has widely used ILS to determine their students' learning styles with tested and proven reliability [12].

While others learning styles models mostly classify learners into groups, Felder and Silverman describes learners learning styles more detail, distinguishing between preferences on four dimensions (active/reflective, sensing/intuitive, visual/verbal, and sequential/global) [13]. Therefore, every student has a preference for each of the four dimensions [14].

\section{INITIAL QUESTIONNAIRE}

An initial questionnaire was distributed to 30 students in STIMIK Pro Visi Semarang, during the second semester 2013/2014. The purpose of this questionnaire is to analyze whether the student needs an elearning platform to help them in learning UML. The students involved in the questionnaire listed in Software Engineering 1 class. The following are subject to questions

1. The attitude of the students towards UML learning

2. The effectiveness of the instructor while giving lectures syllabus

3. Frequency of interaction between students and faculty during the learning UML

The questionnaire also asked students about their readiness to have an alternative learning materials via the web, such as:

1. Frequency of students looking for additional learning materials from the internet

2. The tendency to use online learning in the future (if provided by the institution)

3. Students behavior toward various multimedia learning materials

The last part of the questionnaire leaving two open questions for students to write down their comments and suggestions on how they want the UML material served, for future improvement.

Result of the initial questionnaire show that more than half of the respondents think that UML is too confusing, this is caused by how learning is organized, prepared, delivered, the availability of reference materials for accessed, and lecturer expertise. About half of the respondents also rarely seek additional information regarding UML online. Some of the respondents sought additional information regarding UML online, but did not find the desired UML learning materials. It decreased the interest of respondents to search the material at other time. The future trend of using online learning (if provided by the institution) responded well by respondents. This gives a very good indication that online UML learning modules can be additional help for students to learn the UML better. Overall, students of STIMIK Pro Visi Semarang ready to undergo the online learning modules to help learning UML better. Online learning module is equipped with a variety of multimedia elements to help students learn UML better.

\section{ADAPTIVE ONLINE MODULE PROTOTYPE DESIGN}

\subsection{Process Flow}

Process flow that will be applied in the prototype adaptive online module need to be identified, as shown in Figure 1. The explanation is as follows:

1. The first step the system will provide a Felder and Solomon Index of Learning questionnaire to the students, the results of the questionnaire will determine the student's learning style 
2. If the value of understanding parameter is global, system will show summary of the material.

3. Next if the value of the input parameter is verbal, system gives examples and explanations verbally; otherwise the value is visual, system gives examples and explanations visually.

4. If the perception parameter value is sensing it gives an example before the explanation.

5. If the value of perception parameter is intuitive it gives an explanation before the sample.

6. Link discussion will be granted if the processing parameter value is active.

7. The navigation system is determined by the value of parameter understanding. On global value, it will display choice of material in dropdown in which user may choose freely while sequential value will display navigation as next / previous.

8. In the last section, if the processing parameter value is reflective, it display question as feedback.

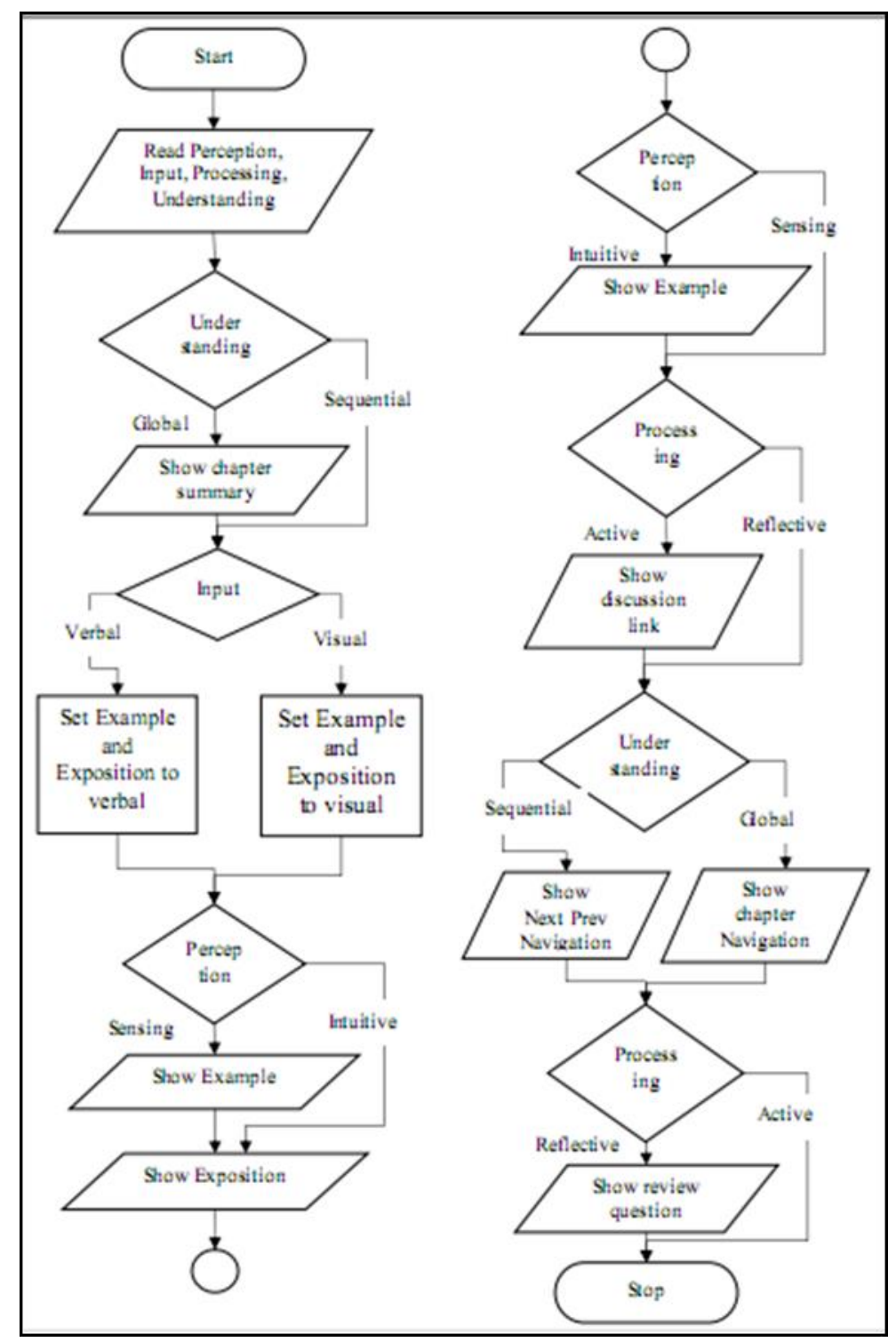

Figure 1. Process Flow of Adaptive Online Module Prototype

\subsection{Functional needs using Use Case}

Use Case System is divided into three, namely the use case for the administrator, the use case for teachers, and the use case for students. The third use case illustrates the interaction between actors to use case describes the functional of a sub-system which is the domain of the actor. Use case for students as shown in Figure 2. 


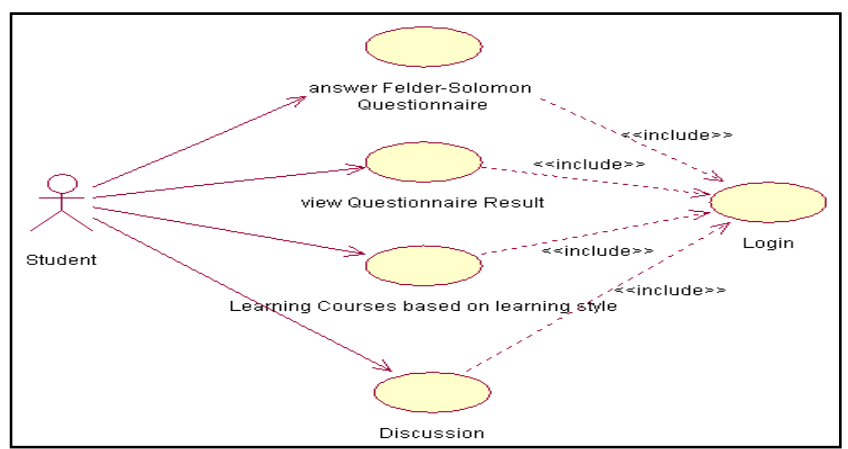

Figure 2. Use Case for Student

\subsection{Database Design}

The prototype of adaptive online module uses database as storage media. The tables designed in the database are shown in Figure 3.

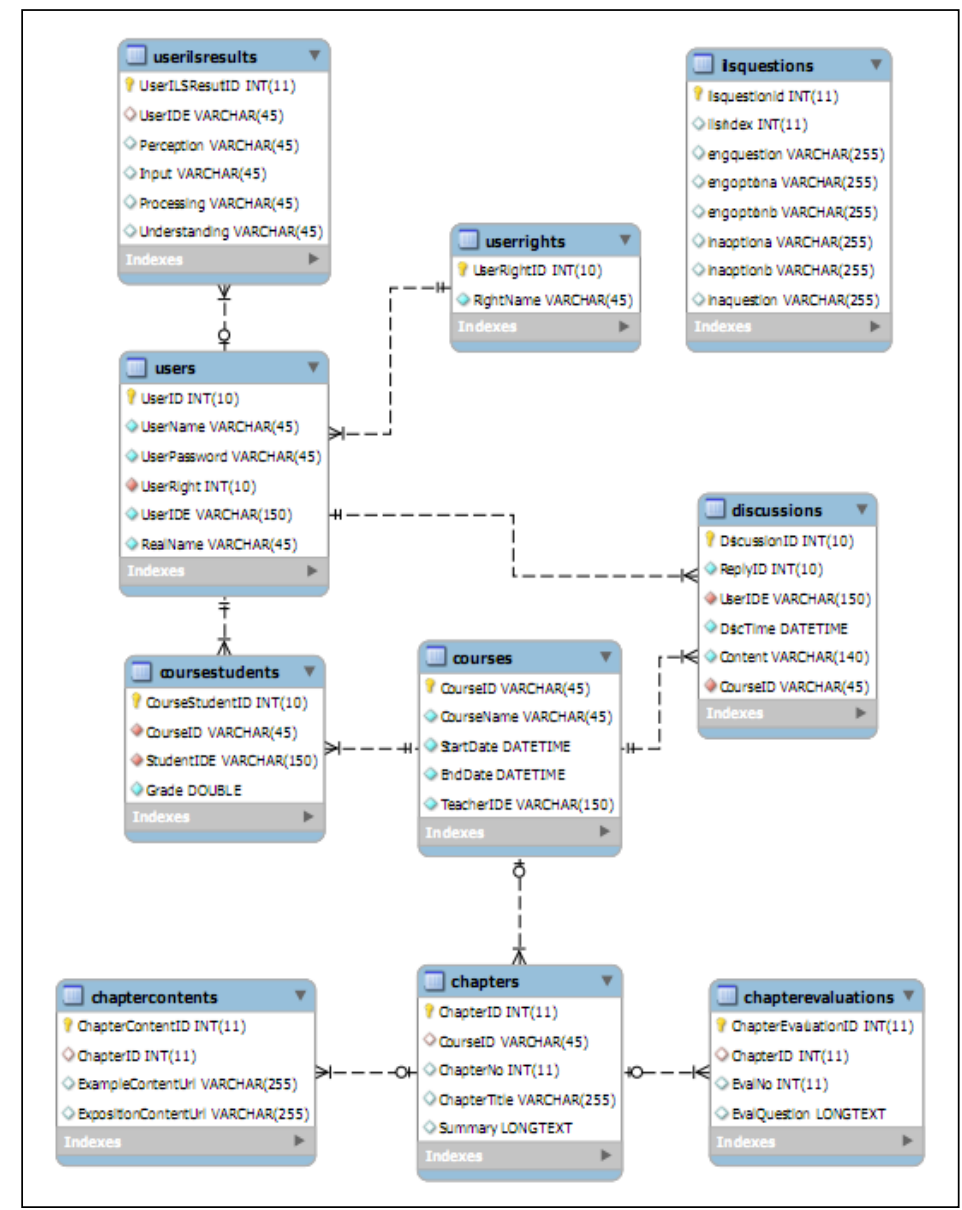

Figure 3. Database Design of Adaptive Online Module Prototype

\subsection{User Authority}

In the adaptive online module prototype, there are three different users: Teachers, administrators and students. Administrators have full control of the entire system. Teachers have access to design specific learning (course). After Teacher finished designing the study, the administrator will integrate and upload them to the system module is accessible online for students. On the other hand, students can only access the 
learning uploaded by the teacher after their learning style determined via filling out the online questionnaire. Then, the system gives the students learning material, in the form of navigation and content, according to its learning style.

\section{RESULTS AND DISCUSSION}

Student page view is a view that would be seen by the student users of adaptive online module prototype. Students may access the adaptive online module via the browser found on personal computers, tablets and smartphones. Page of student view at the implementation stage are as follow:

\subsection{Student Home Page}

The first step page shown to students in accessing the online adaptive prototype module is login page. Students are required to log in by filling out the username and password. Students do not have an account yet, can be registered by the administrator.

Students who have successfully logged in will go to the student main page. If the students' learning style has been classified, then students will see a page listing the course followed by the student. Students can choose the option to open the course material or discussions. Logout button used when a student wants to sign out of this adaptive online module prototype. Student's main page and menu of choice can be seen in Figure 4.

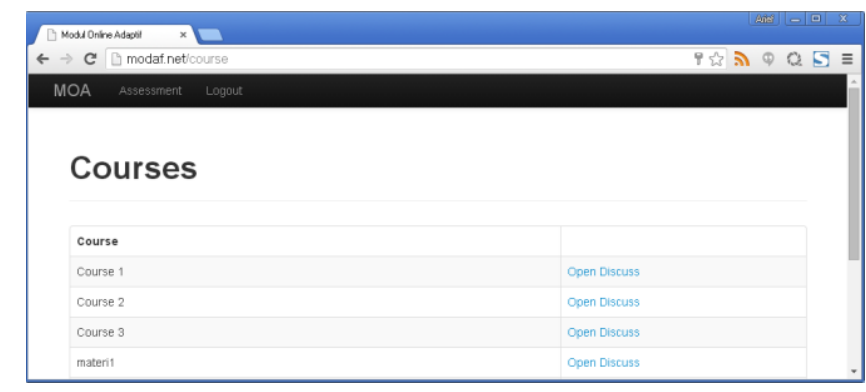

Figure 4. The Main Page of the Student

\subsection{ILS Questionnaire (Assessment) Page}

This page will appear before main page if the student has not done filling out the ILS questionnaire. The questionnaire, as shown in Figure 5, determines student learning style which makes the learning environment change.

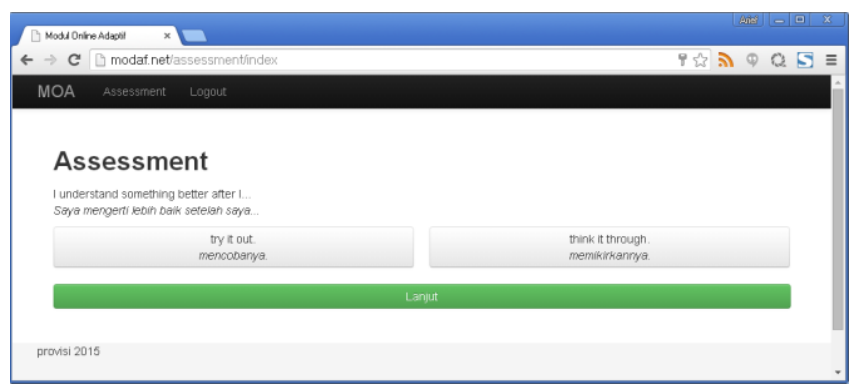

Figure 5. Page of Questionnaire ILS

This assessment contains 44 questions with two possible answers which will appear one by one. After all questionnaires have been answered, it will produce results page, as shown in Figure 6. 


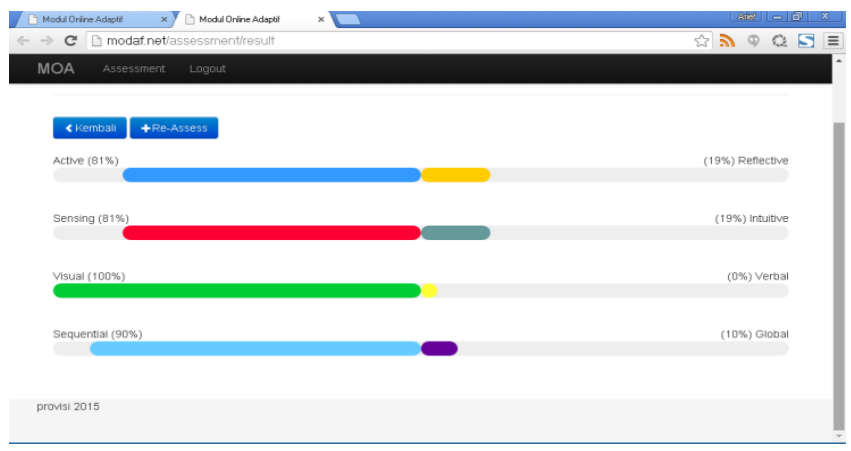

Figure 6. Results Page of Questionnaire ILS

\subsection{Content Page}

Content page will display the learning material according to the student's learning style. As example, if a student, based on the ILS questionnaire, has visual and sequential learning style then system shows visual material in sequential manner as shown in Figure 7.

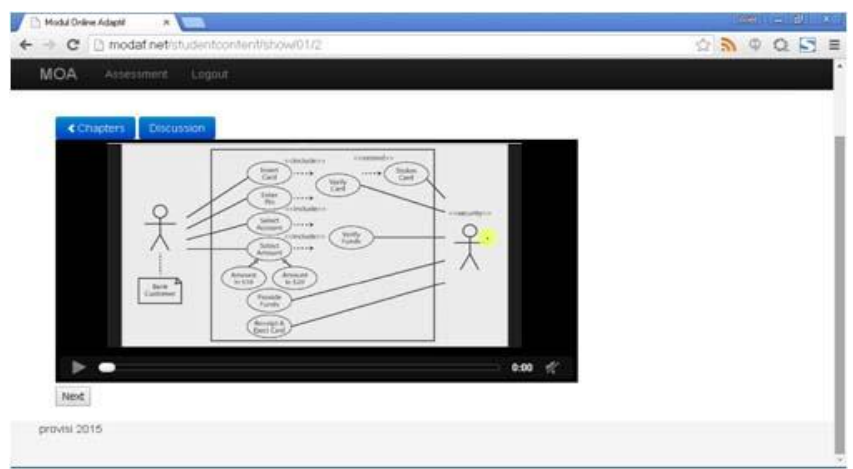

Figure 7. Materials page for students with visual and sequential learning style

The purpose of user acceptance test is to obtain feedback from the user, in this case the students, by distributing questionnaires to 30 students who attend Software Engineering 1 lecture. The questionnaire put the emphasis on the effectiveness of Online Adaptive Module Prototype, whether the prototype helps them to learn UML better or not.

Result from the obtained users' feedback, shows that about $65 \%$ of the students stated the prototype has effective user interface design. For graphic elements used in this prototype, only $42 \%$ of users stating that the graphics element help them visualize UML material, it is a good indication for further development. For users, the learning activities provided by the prototype made them remember the lesson easier, although only $52 \%$ said things like that. Therefore, for the development of this prototype, especially in terms of creative content, must be planned and designed by an instructional designer and expert in UML. As many as $65 \%$ of users stated that the learning path presented in this prototype to help them understand the UML material well.

\section{CONCLUSION}

Prototype of adaptive online module provide UML learning materials as addition to traditional learning. It helps student to visualize the material that hard to understand by text only. It also helps students by the adaptive nature of prototypes that show the content according to their learning style. This prototype focus is limited on small part of UML, as not overall UML material covered yet. 


\section{ACKNOWLEDGEMENTS}

Researchers would like to thank to the Ministry of Research and Technology - Higher Education (KEMENRISTEK-DIKTI) which provide fund for this research.

\section{REFERENCES}

[1] S. Mrdalj and V. Jovanovic, "UML Coverage in Systems Analysis and Designs Textbook," Issues In Information Systems, vol/issue: 5(1), pp. 233-239, 2004.

[2] V. Fredriksen, "Wide Gap Amongst Developers' Perception of the Importance of UML Tools, Developer Eye Study Reveals," ExpressPressRelease, http://www.pr9.net/comp/development/1674 april.html, 2005.

[3] M. R. M. Veeramanickam and N. Radhika, "A Smart ELearning System for Social Networking," International Journal of Electrical and Computer Engineering (IJECE), vol/issue: 4(3), pp. 447-455, 2014.

[4] H. Wang, et al., "Adaptive Presentation for Effective Web- based Learning of 3D Content," IEEE International Conference on Advanced Learning Technologies (ICALT '04), pp. 136-140, 2004.

[5] P. Brusilovsky and C. Peylo, “Adaptive and Intelligent Web-based Educational Systems," International Journal of Artificial Intelligence in Education, vol/issue: 13(2-4), pp. 159-172, 2003.

[6] J. Canavan, "Personalised E-Learning through Learning Style Aware Adaptive Systems," MS Thesis, https://www.scss.tcd.ie/publications/tech-reports/reports.05/TCD-CS-2005-08.pdf, 2004.

[7] B. Bontchev and D. Vassileva, "Adaptive Edutainment in UML," Proceeding of the 8th WSEAS International Conference on Educational Technologies (EDUTE'12), pp. 129-134, 2012.

[8] C. Karagiannidis and D. Sampson, "Accommodating Learning Styles in Adaptation Logics for Personalised Learning Systems," Proceeding of World Conference on Educational Multimedia, Hypermedia and Telecommunication (ED-MEDIA 02), pp. 1715-1726, 2002.

[9] G. V. Abraham, et al., "Adaptive e-Learning Environment using Learning Style Recognition," International Journal of Evaluation and Research in Education (IJERE), vol/issue: 2(1), pp. 23-31, 2013.

[10] R. M. Felder and L. K. Silverman, "Learning and Teaching Styles in Engineering Education," Engineering Education, vol/issue: 78(7), pp.674-681, 1988.

[11] S. R. Viola, et al., "Analysis of Felder-Silverman Index of Learning Styles by a Data-driven," Proceeding Eighth IEEE International Symposium on Multimedia (ISM'06), pp. 959-964, 2006.

[12] R. M. Felder and J. Spurlin, "Applications, Reliability, and Validity of the Index of Learning Styles," International Journal of Engineering Education, vol/issue: 21(1), pp. 103-112, 2005.

[13] S. Graf and Kinshuk, "Providing Adaptive Courses in Learning Management Systems with Respect to Learning Styles," Proceedings of the World Conference on E-Learning in Corporate, Government, Healthcare, and Higher Education," pp. 2576-2583, 2007.

[14] S. Graf and Kinshuk, "An Approach for detecting Learning Styles in Learning Management Systems," Proceedings of the Sixth International Conference on Advanced Learning Technologies (ICALT'06), pp.161-163, 2006.

\section{BIOGRAPHIES OF AUTHORS}

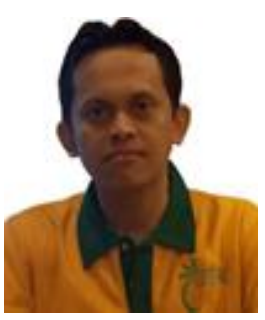

Arief Hidayat is currently working as a lecturer in Dept. of Information System, STIMIK Pro Visi Semarang, Indonesia. He has a lot of teaching, research, and community service experience. He received his Bachelor degree in Computer Engineering from Dian Nuswantoro University, Semarang, in 1999, and Master degree in Information System from Diponegoro University, Semarang, in 2011. His main research work focuses on e-learning, m-learning, adaptive and personalized learning.

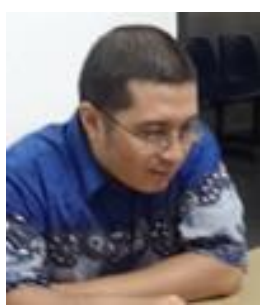

Victor G. Utomo is currently working as a lecturer in Dept. of Computer Engineering, STIMIK Pro Visi Semarang, Indonesia. He has a lot of programming experience. He received his Bachelor degree in Electric Engineering from Kristen Satya Wacana University, Semarang, in 2005, and Master degree in Information System from Diponegoro University, Semarang, in 2013. His work on research mainly on distributed application, service oriented application and cloud computing. 